\title{
Numerical analysis of light-weight air foamed soils using dredged materials for soft ground improvement method
}

\author{
Gil Lim Yoon ${ }^{\text {i) }}$ and Sun Bin Kim ${ }^{\text {ii) }}$ \\ i) Principal Research Scientist, Coastal \& Environmental Engineering Division, Korea Institute of Ocean Science \& Technology, 787 \\ Haean-ro, Sangrok-gu, Ansan, 426-744, Korea. \\ ii) Research Scientist, Coastal \& Environmental Engineering Division, Korea Institute of Ocean Science \& Technology, 787 Haean-ro, \\ Sangrok-gu, Ansan, 426-744, Korea.
}

\begin{abstract}
This paper presents the results of a numerical investigation on applicability of light-weight air foamed soils (LWFS) for soft ground improvement, which are made by mixing dredged soils, cement, and air foam to reduce unit-weight and to increase compressive strength. The engineering properties of LWFS were comprehensively investigated based on the previous experimental tests. And three dimensional numerical models which reflect soft ground conditions were adopted to evaluate the applicability of LWFS compared to soft ground improvement methods such as SCP(Sand Compaction Piles) and DCM(Deep Cement Mixing Piles). A number of cases were analyzed using a stress-pore pressure coupled model. The results indicated that LWFS method enables to reduce settlement and lateral ground flow than SCP method and enable to reduce residual settlement than DCM method in the scope of this paper. Also it was revealed that such effects are affected by the properties of LWFS such as lightness, appropriate strength and stiffness and Poisson's ratio.
\end{abstract}

Keywords: light-weight air foamed soils (LWFS), dredged soils, soft ground improvement, finite element analysis

\section{INTRODUCTION}

Dredged soils generated from new construction of large-scale ports and coastal maintenance works have been open-dumped at the designated sea area or reclaimed in nearshore site which requires a large of land area and may causes neighboring environmental pollutions. It is required that development of recycling techniques and new treatment system to use a significant amount of dredged soils. Among them, this paper focuses on light-weight air foamed soils (LWFS), which are to both reduce unit weight and increase compressive strength of raw materials. LWFS are expected to substitute of normal in situ soils used in backfill to earth structures and embankment materials for soft ground improvement because of certain effectiveness such as decreasing settlement and earth pressure due to its lightness.

Several studies during a decade have been carried out to assess the physical and mechanical properties of LWFS including specific gravity, compressive strength, deformation and creep characteristics and permeability (Tsuchida et al., 1996; JSGE, 1998; Kim \& Lee, 2002; Yoon \& Kim, 2004; Yoon \& Yoo, 2004; Yoon \& Yoo, 2005; Song, 2008; Hwang et al., 2010). Based on such previous studies, this paper discusses an applicability of LWFS for soft ground improvement through the numerical analysis of stability and settlement of the ground.

\section{ENGINEERING PROPERTY OF LWFS}

LWFS is a kind of soil mixtures which is made by mixing dredged soils, cement, water and air foam. Its unit weight $(\gamma)$ is around $6 \sim 12 \mathrm{kN} / \mathrm{m}^{3}$ and the unconfined compressive strength $\left(q_{u}\right)$ is a maximum of $1,000 \mathrm{kPa}$ depending on the contents of air form and cement. Deformation modulus of LWFS is known between $15 \sim 160 \mathrm{MPa}$ in the form of $E_{50}$ which is affected by a compressive strength. Creep characteristic is also known to be very small under its yield stress. In case of permeability $(k)$, it is known as practically almost equal to silt-clay. Table 1 presents the engineering properties of LWFS.

Table 1. Engineering properties of LWFS

\begin{tabular}{ll}
\hline Item & Characteristics \\
\hline Unit weight & $\gamma=6 \sim 12 \mathrm{kN} / \mathrm{m}^{3}$ \\
\hline Strength & $q_{u, \max }=1,000 \mathrm{kPa}$ \\
& $S_{u}=1 / 2 q_{u}(\phi=0)$ \\
\hline Stiffness & $q_{u}=200 \sim 800 \mathrm{kPa} \rightarrow E_{50}=15 \sim 160 \mathrm{MPa}$ \\
& $v=0.05 \sim 0.15$ \\
\hline Creep & very small under yield stress \\
\hline Permeability & $k=10^{-6} \sim 10^{-5} \mathrm{~cm} / \mathrm{sec}$ \\
\hline
\end{tabular}




\section{NUMERICAL ANALYSIS}

\subsection{Case study}

A hypothetical embankment section over soft ground was considered. Details of the case are given under the followings. The embankment geometry with LWFS, deep cement mixing (DCM) and sand compaction pile (SCP) reinforced ground is given in Fig. 1, showing only right half of the domain on account of the line of symmetry about its center. As seen in Fig. 1, the embankment filled with sandy soil is $68 \mathrm{~m}$ wide and $6 \mathrm{~m}$ high with sloping $1 \mathrm{~V}: 2 \mathrm{H}$ toward the side. Soil profile with a clay layer, $10 \mathrm{~m}$ deep overlying a stiff clay layer, is assumed to be very soft because of the standard penetration test (SPT) blow count $\mathrm{N}$ value less than 3. A $1.0 \mathrm{~m}$ thick dense sand layer is assumed to be placed as a sand mat.

LWFS are placed up to $10 \mathrm{~m}$ deep on a stiff clay layer sloping $1 \mathrm{~V}: 2 \mathrm{H}$ after dredging or excavating soft clay layer. Cement mixing piles are also installed above a stiff clay layer. In case of SCP, referring to Fig. 1(c), $700 \mathrm{~mm}$ diameter, SCP extend to the stiff clay layer. The SCP are arranged in a square grid pattern with 1.13 $\mathrm{m}$ center to center spacing, giving the replacement ratio $\left(\mathrm{A}_{\mathrm{E}}\right)$ of $30 \%$. The groundwater table was assumed to be located at the top surface of the clay layer.

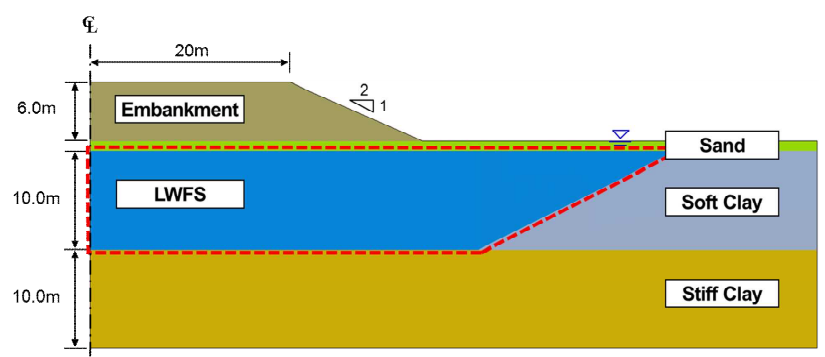

(a) LWFS

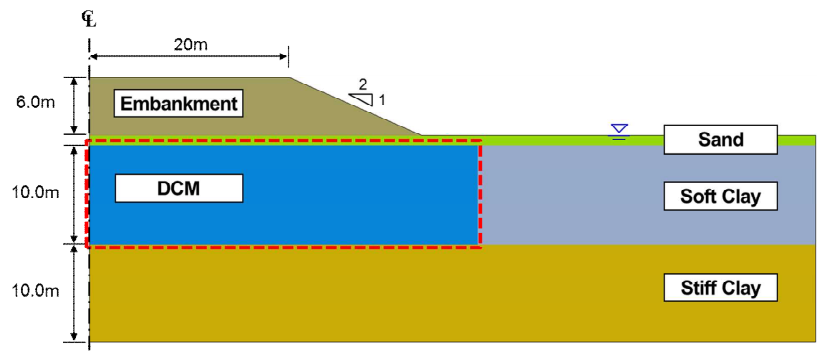

(b) DCM

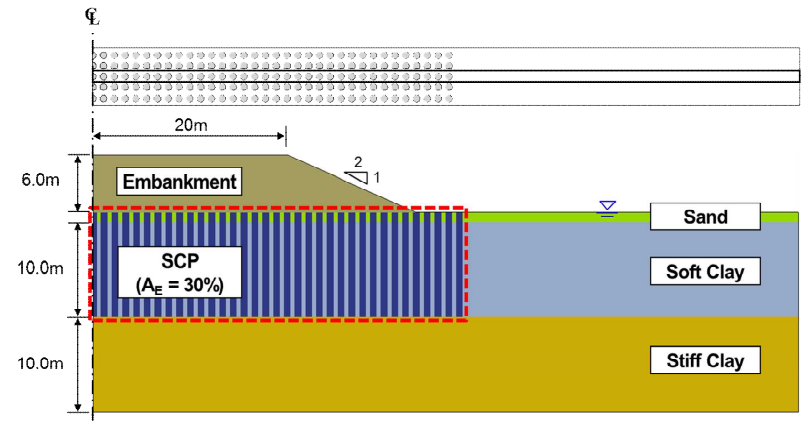

(c) SCP

\subsection{Finite element modeling}

With regard to the constitutive modeling, the soft clay soil was modeled using the Modified Cam-Clay material model and a linear-elastic, perfectly plastic model with the Mohr-Coulomb failure criterion were used to model the fill and sand mat, LWFS, DCM and SCP columns. A summary of the constitutive modeling of material parameters is given in Table 2 .

Table 2. Material properties for finite element analysis

\begin{tabular}{cccccccc}
\hline Material & $\begin{array}{c}\gamma_{\text {sat }} \\
\left(\mathrm{kN} / \mathrm{m}^{3}\right)\end{array}$ & $\begin{array}{c}E \\
(\mathrm{GPa})\end{array}$ & $\begin{array}{c}c \\
(\mathrm{kPa})\end{array}$ & $\begin{array}{c}\phi \\
(\mathrm{deg} .)\end{array}$ & $e$ & $v$ & $\begin{array}{c}k \\
(\mathrm{~cm} / \mathrm{s})\end{array}$ \\
\hline LWFS & 15.7 & 55 & 150 & 0 & 2.0 & 0.15 & $4.86 \times 10^{-6}$ \\
\hline DCM & 25.0 & 20,000 & - & - & 1.0 & 0.20 & $1.00 \times 10^{-8}$ \\
\hline SCP & 20.0 & 20 & 0 & 33 & 1.5 & 0.30 & $1.00 \times 10^{-3}$ \\
\hline Fill & 19.0 & 40 & 10 & 30 & - & 0.40 & - \\
\hline Sand mat & 19.0 & 15 & 0 & 28 & - & 0.30 & - \\
\hline Soft clay & 20.0 & $\lambda=0.36, \kappa=0.2, \mathrm{a}_{0}=50, \mathrm{M}=1.0$ & 1.5 & 0.30 & $1.16 \times 10^{-6}$ \\
\hline Stiff clay & 20.0 & $\lambda=0.10, \kappa=0.01, \mathrm{a}_{0}=300, \mathrm{M}=1.0$ & 1.5 & 0.30 & $1.16 \times 10^{-6}$ \\
\hline
\end{tabular}

* $\gamma_{\text {sat }}=$ unit weight, $E=$ deformation modulus, $c=$ cohesion, $\phi=$ internal friction angle, $e=$ void ratio, $v=$ Poison's ratio, $k=$ permeability, $\lambda=$ plastic slope, $\kappa=$ elastic slope, $a_{0}=$ initial yield surface size, $M=$ critical stress ratio

A commercial finite-element code ABAQUS ver. 6.10 (Abaqus 2010) was used for analysis in this study to take advantage of its robustness in numerical solution strategy for nonlinearity of soil and stress-pore pressure coupled problems.

The 3D FE models for the right half of the section were adopted due to the symmetry about its centerline as shown in Fig. 2. For SCP, with reference to Fig. 2(c), the equivalent full 3D model covers the lateral portion of the domain but with only one row of SCP. The models are horizontally fixed on the vertical sides, and full fixity on the bottom boundary is assumed. For the hydraulic boundary conditions, the phreatic level is set at the top surface to generate a hydrostatic pore water pressure profiling in the domain with the top boundary of the clay layer having a zero pore pressure boundary condition to model free drainage.

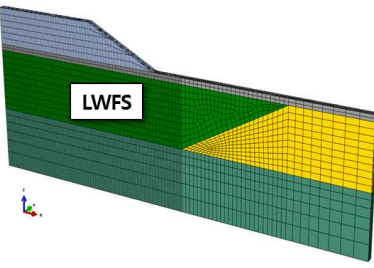

(a) LWFS

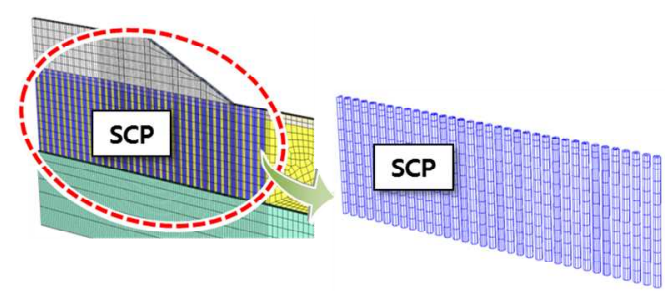

(c) SCP

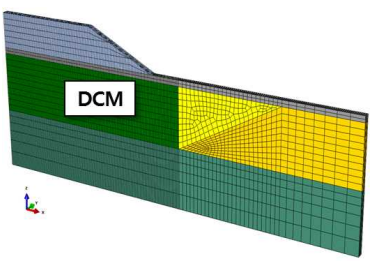

(b) DCM
Fig. 1. Design conditions

Fig. 2. 3D finite element model 
The 8-node stress-pore pressure coupled brick elements (C3D8P) were used to represent the clay layer, LWFS, DCM and SCP below groundwater table. Sand mat and fill layer were discretized using 8-node brick elements with reduced integration (C3D8R).

After establishing the initial stress and pore pressure conditions with appropriate boundary conditions, the LWFS, DCM and SCP were activated as wishedin-place. The embankment construction was then simulated in three equal stages with a $2 \mathrm{~m}$ fill placement. The embankment loading was simulated by adding layers of elements simulating the filling in all models. Each embankment filling placement was planned to be completed in 15 days. In case of the SCP, this was followed by 10 day consolidation periods. After full placement of the embankment, the numerical analysis was carried out until the excess pore water pressure approach below a specified near zero value.

\subsection{Analysis result}

The numerical analysis results of above-mentioned three different ground improvements were compared with respect to the settlement, excess pore pressure and effective stress, respectively, in the ground.

Fig. 3 shows the progressing with time of the settlement $\left(S_{t}\right)$ and the excess pore water pressure $(\Delta u)$. The $S_{t}$ was measured at the bottom of embankment and the $\Delta u$ was monitored at the bottom of soft clay layer. Those were also compared with the results of unimproved soft ground conditions.

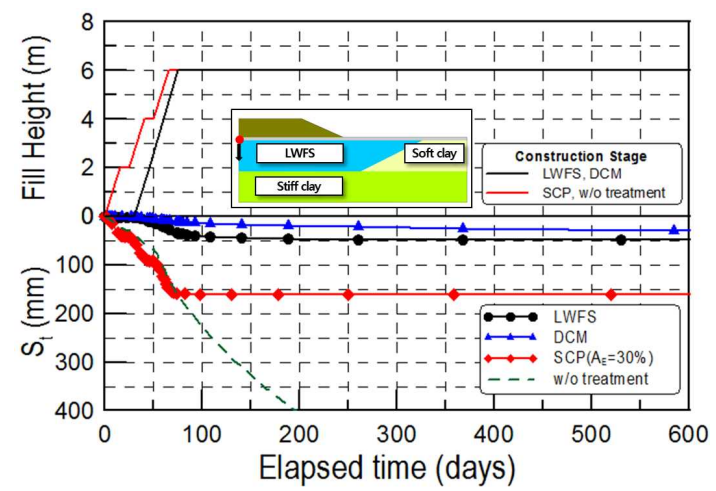

(a) Time-settlement

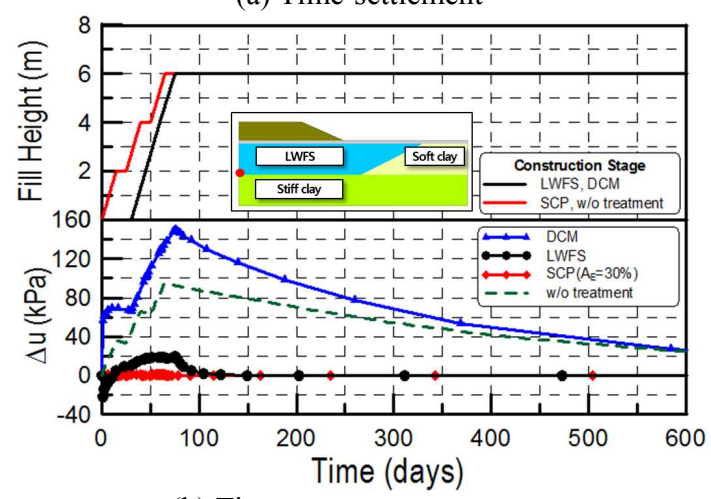

(b) Time-excess pore pressure

Fig. 3. Time history curves for settlement and excess pore water pressure dissipation
A comparison between the soft ground improve methods reveals that LWFS method gives nearly $70 \%$ reduced $S_{t}$ when compared to the SCP method, and the difference of $S_{t}$ with the DCM method is just about 15 $\mathrm{mm}$ in terms of final settlements as shown in Fig. 3(a). Fig. 3(b) shows that the $\Delta u$ tends to dissipate directly after the embankment surcharge in the ground improved by SCP. However, the $\Delta u$ in the composite ground improved by DCM increases significantly with step-loading and its dissipation rate also shows very low with time. These may be because permeability of the composite ground by DCM is almost same with soft clay layer and its unit weight is relatively much larger than soft clay as well as LWFS. Meanwhile, the $\Delta u_{\max }$ in the ground replaced by LWFS tends to drop as much as $1 / 7 \sim 1 / 8$ quantitatively compared to the DCM or unimproved soft ground. This result leads to reduce consolidation time and total settlement. Such trends are thought to be due to the lightness of LWFS.

Fig. 4(a) presents the residual settlement $\left(S_{r}\right)$ after completing fill placement. And Fig. 4(b) represents $S_{r}$ as the normalized form $\left(S_{r} / S_{c}\right)$. Note that $S_{c}$ is defined as the settlement immediately after completing fill placement. As shown, the $S_{r}$ in the composite ground by DCM is relatively large to be nearly 3 times of the $S_{c}$ over 5 years, whereas in the SCP and LWFS it is just $10 \sim 20 \%$ of $S_{c}$ during the same time period. This illustrates that LWFS enhances long term serviceability of embankment in the practical aspects.

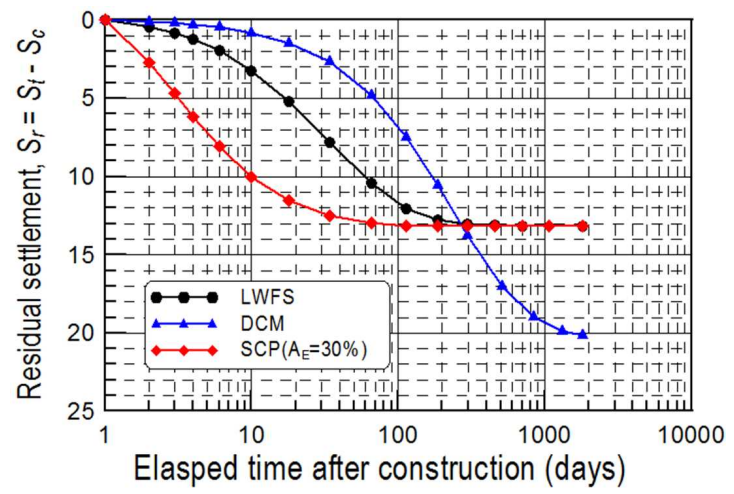

(a) Residual settlement

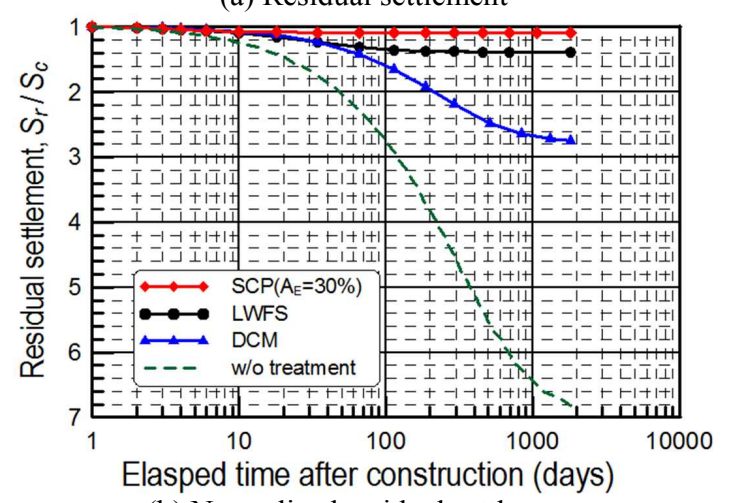

(b) Normalized residual settlement

Fig. 4. Time history curves for residual settlement after completing fill placement 


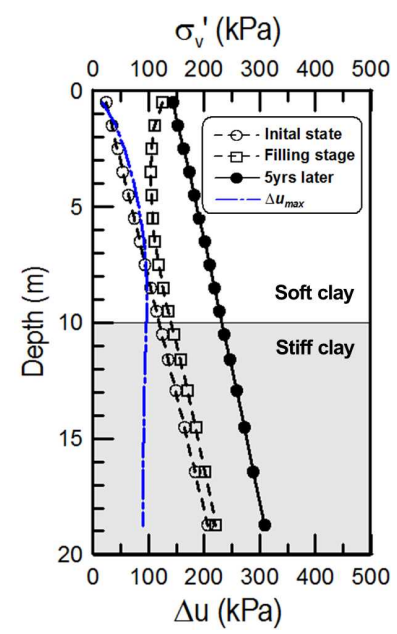

(a) w/o treatment $\sigma_{\mathrm{v}}^{\prime}(\mathrm{kPa})$

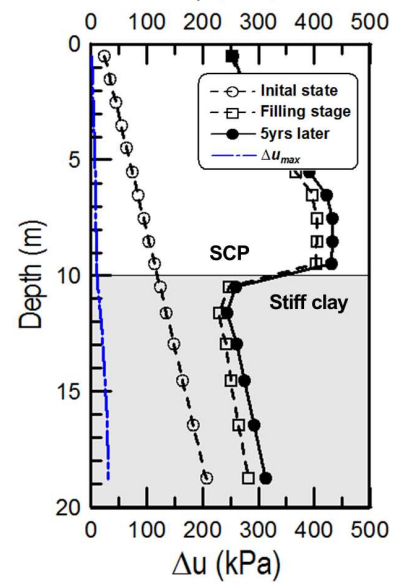

(c) DCM

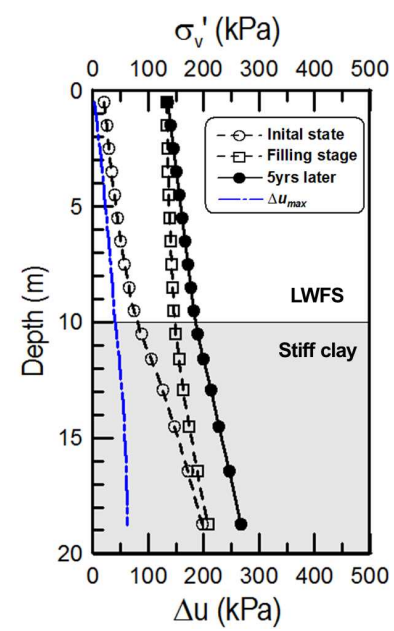

(b) LWFS

$\sigma_{\mathrm{v}}^{\prime}(\mathrm{kPa})$

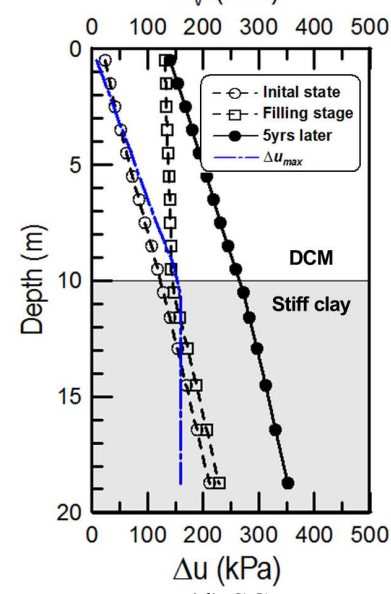

(d) SCP

Fig. 5. Vertical effective stress \& excess pore pressure profiles

The effects of LWFS can be illustrated in Fig. 5. As shown in figure, the vertical effective stress $\left(\sigma_{v}{ }^{\prime}\right)$ and the excess pore pressure $(\Delta u)$ is presented with depth at the middle of the embankment. It can be observed that in SCP ground, the $\Delta u$ is very small whereas the $\sigma_{v}{ }^{\prime}$ in the sand column rapidly increases directly after fill placement, then after 5 years later the $\Delta \sigma_{v}{ }^{\prime}$ is insignificant. In the case of DCM, in the embankment loading stage the $\sigma_{v}$ ' increases somewhat in the upper part of composite ground, and then after 5 years later increases remarkably as the equivalent of the $\Delta u$. It can explain reasons why initial consolidation settlement of the improved ground by SCP and residual settlement of the composite ground by DCM are comparatively large.

As regards LWFS, before loading, the $\sigma_{v}$ ' in the replaced ground is relatively small compared to others due to its lightness. During the fill placement, $\sigma_{v}$ ' increases to be similar with DCM's. However, after 5 years later, the $\Delta \sigma_{v}{ }^{\prime}$ is not distinguished because the $\Delta u$ is less than $1 / 3$ of DCM's. It can be also explained that consolidation settlement in another compressible soil layers at the bottom of replaced or composite ground by LWFS may be reduced.

Fig. 6 7 show ground surface settlement and lateral deflection profiles, respectively, in the improved ground for the 5 years after final fill placement. It can be seen that LWFS method enables to reduce lateral ground flow as well as settlement compared to SCP method. Such positive effects are considered due to the lightness, appropriate strength and stiffness of LWFS. Also, as above mentioned, those may be affected by Poisson's ratio $(v)$ of LWFS which is relatively small in the range of $0.05 \sim 0.15$.

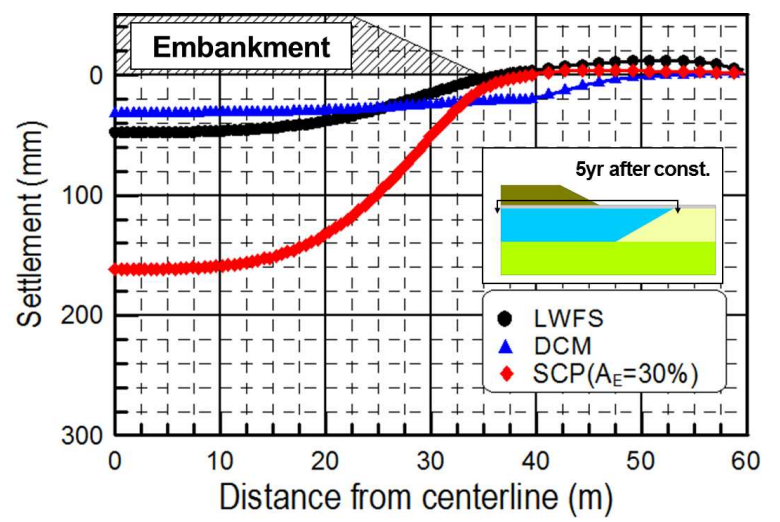

Fig. 6. Ground surface settlement profiles

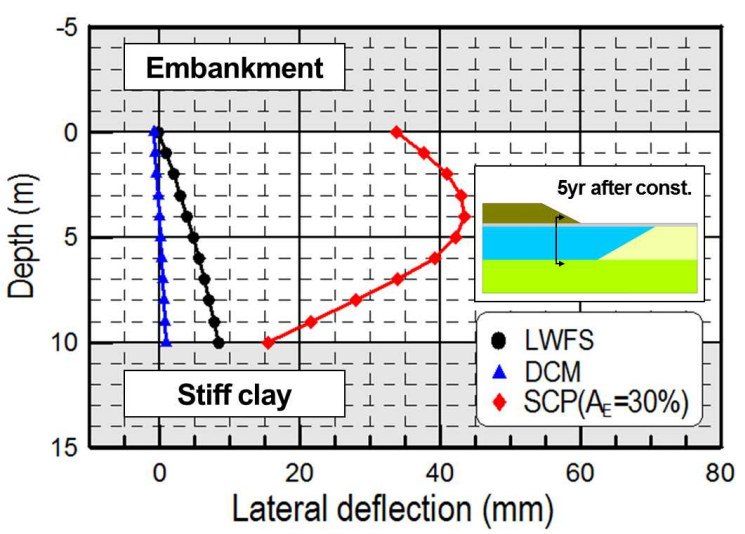

Fig. 7. Lateral deflection profiles

\section{CONCLUSIONS}

This paper presents the numerical analysis of applicability of lightweight air foamed soils (LWFS) for soft ground improvement. Three dimensional stress-pore pressure coupled models were adopted to investigate the applicability of LWFS. Also the analysis results were compared to those of SCP and DCM methods. A comparative study indicated that LWFS method enables to reduce settlement and lateral ground flow than SCP method, and enable to reduce residual settlement than DCM method in the scope of this paper. Also it may be judged that such effects are affected by the properties of LWFS such as lightness, appropriate strength and stiffness and Poisson's ratio. 


\section{ACKNOWLEDGEMENTS}

This work was carried out as parts of the "Research on Eco-friendly Procurement, Reclamation and Transferring Technology of Transport Distance more than $30 \mathrm{~km}$ of Dredged Materials" research project supported by the Korea Agency for Infrastructure Technology Advancement (KAIA).

\section{REFERENCES}

1) JSGE. (1998): Application and physical properties of Super Geomaterial (SGM), Japanese Society of Geotechnical Engineering (in Japanese).

2) Tsuchida T, Okumura T, Takeuchi T. and Kishda T. (1996): Development of light-weight fill from dredging, Proceedings of the 13th Int. Conf. on environmental Geotechnics, Kyoto University, 1(1), 415-428 (in Japanese).

3) ABAQUS (2010): Analysis User's manual, version 6.10, Dassault Systemes.

4) Hwang, J. H., An, Y. K. and Kim, T. H. (2010): Effect of water on the lightweight air-mixed soil containing silt used for road embankment, Journal of Korean Geotechnical Society, 26(2), 23-32 (in Korean).

5) Kim, Z. C. and Lee, C. K. (2002): Mechanical characteristics of light-weighted foam soil consisting of dredged soils, Journal of Korean Geotechnical Society, 18(4), 309-317 (in Korean).

6) Song, J. H. (2008): Analysis of compressive strength of lightweight air-mixed soil according to the properties of soil, Journal of Korean Geotechnical Society, 24(11), 157-166 (in Korean).

7) Yoon, G. L. and Kim, B. T. (2004): Compressibility and strength of the lightweight air formed soils, Journal of Korean Geotechnical Society, 20(4), 5-13 (in Korean).

8) Yoon, G. L and Yoo, S. K. (2004): Strength and deformation characteristics of lightweight soil using in situ soils, Journal of Korean Geotechnical Society, 20(9), 125-132 (in Korean).

9) Yoon, G. L and Yoo, S. K. (2005): Behaviors of lightweight foamed soils considering underwater curing and water pressure conditions, Journal of Korean Geotechnical Society, 21(4), 21-29 (in Korean). 